\title{
Synthesis of ZnO Nanoparticles by a Novel Surfactant Assisted Amine Combustion Method
}

\author{
Yendrapati Taraka Prabhu' ${ }^{1}$, Kalagadda Venkateswara Rao ${ }^{1}$, \\ Vemula Sesha Sai Kumar ${ }^{1}$, Bandla Siva Kumari ${ }^{2}$ \\ ${ }^{1}$ Centre for Nano Science and Technology, Institute of Science and Technology, \\ Jawaharlal Nehru Technological University, Hyderabad, India \\ ${ }^{2}$ Department of Botany, Andhra Loyola College, Vijayawada, India \\ Email:prabusj@gmail.com
}

Received December 24, 2012; revised January 23, 2013; accepted January 30, 2013

\begin{abstract}
Zinc oxide nano powder synthesis is carried by a single step simple and fast combustion method using Zinc nitrate as precursor, HMTA as fuel material and non-ionic surfactant (Triton-X 100). The X-Ray diffraction (XRD) analysis revealed that the synthesized $\mathrm{ZnO}$ nanopowder has the pure wurtzite structure. The $\mathrm{ZnO}$ powder shows polycrystalline nature having the crystallite size $21.25 \mathrm{~nm}$. Crystallite size is calculated using Debye-Scherrer's and Williamson-Hall equations. Porosity, Cell Volume, Micro strain, Morphology Index, Lorentz factor and Lorentz Polarization factor are also studied. From differential thermal analysis (DTA) \& thermo gravimetric (TGA) it has been confirmed that nano powder has the phase purity. The weight loss percentage of the sample is $2.8385 \%$. The particle size obtained $29 \mathrm{~nm}$ is in good agreement with the crystallite size calculated from X-Ray Diffraction pattern with the Particle Size Analyzer. The morphology of as prepared Zinc oxide nanopowders are characterized by scanning electron microscope (SEM). From specific area electron diffraction (SAED) pattern has specified the d-spacing and corresponding planes which coincide with the XRD d-spacing and planes.
\end{abstract}

Keywords: HMTA; Transmission Electron Microscope (TEM); Triton-X 100; X-Ray Diffraction (XRD)

\section{Introduction}

Zinc Oxide $(\mathrm{ZnO})$ is a wide band gap semiconductor with wurtzite structure. The physical and chemical properties of nano-scale particles are different when compared with the bulk materials. Nano powders controlled to nanocrystalline size can show atom-like behavior which results from higher surface energy. It is due to the large surface area and wider band gap between the conduction and valence band [1]. There is always a need for the improvement of the synthesis of $\mathrm{ZnO}$ for the Industrial needs with less time and less expensive. Alternate method was proposed by various people Park et al. proposed and reported a novel solution combustion method (SCM) [2]. Noori et al. [3] obtained $\mathrm{ZnO}$ powder with 30 $\mathrm{nm}$ size combustion method using zinc nitrate, urea, glycine and citric acid at neutral $\mathrm{pH}$ and calcination at $500^{\circ} \mathrm{C}$. This zinc oxide powder is widely used in the various applications such as coatings for papers, ointments, and cream lotions to protect against sunburn. Zinc Oxide is used in the functional devices, catalysts, pigments, optical material and other important applications. Therefore in the present paper $\mathrm{ZnO}$ nano crystallites synthesis follows a novel solution combustion synthesis method with surfactant assistance and its structural, op- tical, thermal and morphological characterizations are discussed.

\section{Experimental Details}

The starting materials such as zinc nitrate, HMTA and non-ionic surfactant are used. Freshly prepared aqueous solutions of the chemicals were used for the synthesis of nanoparticles. At room temperature the chemicals are mixed by dropping simultaneously $50 \mathrm{ml}$ of $0.1 \mathrm{M}$ solution of zinc nitrate, $50 \mathrm{ml}$ of $0.15 \mathrm{M}$ solution of HMTA and $0.025 \mathrm{M}$ solution of non-ionic surfactant. The mixture of chemicals was then heated on a hot plate which led the chemical mixture to self-combustion. After combustion the final precipitate is subjected to calcination for $1 \mathrm{hr}$ at $4000 \mathrm{C}$. Thus we successfully obtained a pure $\mathrm{ZnO}$ nano powder in this synthesis. Addition of nonionic surfactant with molecules composed of the hydrophilic head and hydrophobic tail, into precursor solution results in formation of reverse micelles in the gel. Placing the aqueous ions inside these micelles can be effective for controlling the growth of the particles. Surfactant has also the role of fuel in the combustion process. The powder characteristics like crystallites size, particles mor- 
phology and agglomeration are dependent on flame temperature generated during combustion, which is dependent on nature of the fuel and other starting materials such as oxidant.

\section{Results and Discussion}

\subsection{XRD Analysis}

The XRD pattern of the powder is studied with the diffraction angle $25^{\circ}-80^{\circ}$. All the peaks are in $100 \%$ phase matching with the $\mathrm{ZnO}$ hexagonal phase of JCPDF No. 36-1451. It is shown in Figure 1. There are no other characteristic impurities peaks were present which also confirm that the product obtained is in pure phase. The line broadening in the peaks determine the crystallite size of $\mathrm{ZnO}$ to be less than $25 \mathrm{~nm}$. The average crystalline size of the calcined $\mathrm{ZnO}$ powder is estimated by the Scherrer's relation (1) [4].

$$
D=\frac{0.9 \lambda}{\beta \cos \theta}
$$

where $D$ is the average crystalline size $\lambda$ is the $\mathrm{X}$-ray wavelength of $1.54 \AA$, $\theta$ is the Bragg diffraction angle and $\beta$ is the FWHM.

The Willliamson-Hall Equation (2) is

$$
\beta \cos \theta=\frac{K \lambda}{D}+2 \varepsilon \sin \theta
$$

where $\beta$ is the full width at half maximum (FWHM) of the XRD all peaks, $K$ is Scherrer's constant, $D$ is the crystallite size, $\lambda$ the wavelength of the X-ray, $\varepsilon$ the lattice strain, and $\theta$ the Bragg angle. $\beta \cos \theta$ is plotted against $2 \sin \theta$ along $y$ and $x$ axis respectively. Linear extrapolation is employed to this plot, the crystallite size is given by the intercept $K \lambda / D$ and the strain $(\varepsilon)$ is given by slope. Here the average size of the crystal is $21.82 \mathrm{~nm}$. Micro strain is calculated from Williamson-Hall plot equation. The micro strain from the Table $\mathbf{1}$ showed that as the

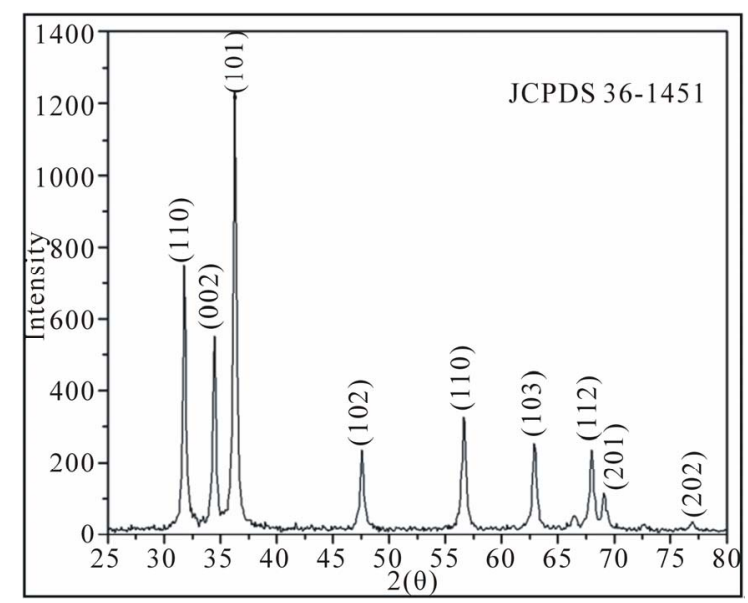

Figure 1. XRD pattern of $\mathrm{ZnO}$ powder prepared by combustion synthesis matching with Zincite phase (PDF361451). average crystallite size decreased the micro strain increased. This might be because of the mechanical surface-free energy of the metastable nanoparticles. Chemical combustion synthesis produced highly porous materials as the synthesized material has less density than the theoretical values [5]. Using the X-ray diffraction pattern the porosity of the calcined samples was determined. The percentage of the porosity was calculated and tabulated in Table 2, according to the following Equation (3). Where $D_{T}$ is theoretical density and $D$ is calculated density from X-ray data using the formula $\left(D=8 \mathrm{M} / \mathrm{Na}_{3}\right)$ where $M$ is the molecular weight, $N$ is Avogadro's number, and " $a$ " is the lattice parameter.

$$
\operatorname{Porosity}(P)=\left(1-\frac{D}{D_{T}}\right) 100
$$

From Table 2 it is noticed that the relationships of fuels with the changes of lattice parameters with the standard parameters. Due to large number of vacancies of oxygen, vacancy clusters, and local lattice disorders present in the interface of $\mathrm{ZnO}$ nanoparticles there is an increase in " $c$ " and decreases in " $a$ " and the volume of the unit cell but there is no apparent changes in the positions and intensities of XRD peaks. Due to the presence of dangling bonds on the surface of $\mathrm{ZnO}$ nanoparticles leads to the lattice relaxation (contraction or expansion).

Units Morphology Index (MI) is developed from FWHM of XRD data. The FWHM of two peaks are related with $\mathrm{MI}$ to its particle morphology. MI is obtained from Equation (4). The MI range for HMTA is from 0.5 to 0.61 . It correlates with its particle sizes. Details are present in Table 3.

$$
\mathrm{M} . \mathrm{I}=\frac{\mathrm{FWHM}_{h}}{\mathrm{FWHM}_{h}+\mathrm{FWHM}_{p}}
$$

where M.I is morphology index, $\mathrm{FWHM}_{h}$ is highest FWHM value obtained from peaks and $\mathrm{FWHM}_{p}$ is value of particulars peak's FWHM for which M.I is to be calculated. The Lorentz-polarization factor is the most important of the experimental quantities that control X-ray intensity with respect to diffraction angle. In the intensity calculations Lorentz factor is combined with the polarization factor and further the variation of the Lorentz's factor with the Bragg angle $(\theta)$ is shown [6-8]. The overall effect of Lorentz factor is to decrease the intensity of the reflections at intermediate angles compared to those in the forward or backward directions. Lorentz factor and Lorentz Polarization factor are calculated from Equations (5) and (6) respectively and tabulated in Table 3.

$$
\begin{gathered}
\text { Lorentz factor }=\frac{\cos \theta}{\sin ^{2} 2 \theta}=\frac{1}{4 \sin ^{2} \theta \cos \theta} \\
\text { Lorentz Polarization factor }=\left(\frac{1+\cos ^{2}(2 \theta)}{\sin ^{2} \theta \cos \theta}\right)
\end{gathered}
$$


Table 1. Lattice parameter, cell volume, crystallite size, c/a ratio, porosity, Williamson-Hall and strain of ZnO nanoparticles calculated from XRD data.

\begin{tabular}{|c|c|c|c|c|c|c|c|c|}
\hline \multirow{2}{*}{ Fuel } & \multicolumn{2}{|c|}{ Unit cell parameters $(\AA ̊)$} & \multirow{2}{*}{$\begin{array}{c}\text { Cell } \\
\text { volume }(\AA ̊)^{3}\end{array}$} & \multirow{2}{*}{$\begin{array}{l}\text { Crystallite } \\
\text { size (nm) }\end{array}$} & \multirow{2}{*}{$c / a$ ratio } & \multirow{2}{*}{ Porosity $\%$} & \multirow{2}{*}{$\begin{array}{l}\text { Willamson- } \\
\text { Hall (nm) }\end{array}$} & \multirow{2}{*}{ Strain } \\
\hline & $a$ & $c$ & & & & & & \\
\hline HMTA & 3.252 & 5.214 & 47.755 & 21.89 & 1.6032 & 0.27 & 12.82 & 0.0303 \\
\hline
\end{tabular}

\subsection{UV-Vis Spectroscopy}

In the Figure 2 the absorption spectrum of $\mathrm{ZnO}$ nanoparticles dispersed in ethanol solution are shown. A typical exciton absorption at $372 \mathrm{~nm}$ is observed in the absorption spectrum correspond to $\mathrm{ZnO}$ nanoparticles. The optical properties of the synthesized $\mathrm{ZnO}$ nanoparticles the band gap and type of electronic transition were determined which are calculated by means of the optical absorption spectrum. When photons of higher energy are larger than band gap of the semiconductor, an electron is transferred from the valence band to the conduction band where there occurs an abrupt increase in the absorbency of the material to the wavelength corresponding to the band gap energy. The relation of the absorption coefficient $(\alpha)$ to the incidental photon energy depends on the type of electronic transition. In this transition if the electron momentum is conserved then the transition is direct, but if the momentum does not conserve this transition it must be attended by a photon, this is an indirect transition $[9,10]$. To analyze the electronic properties of the $\mathrm{ZnO}$ synthesized, the remission function of KubelkaMunk was used $F\left(R^{\prime} \infty\right)$ [11-15]:

$$
F\left(R^{\prime} \infty\right)=\frac{(1-R \infty)^{2}}{2 R^{\prime} \infty}=\frac{\alpha}{S}
$$

where

$$
R^{\prime} \infty=\frac{R \infty(\text { muestra })}{R \infty(\text { estandar })}
$$

$R \infty(1 / 10)$ is the diffused reflectance of a given wavelength, of a dense layer of non transparent infinite material, $\alpha$ is the absorption coefficient $\left(\mathrm{cm}^{-1}\right)$ and $S$ is the dispersion factor, which is independent of the wavelength for particles larger than $5 \mu \mathrm{m}$. $\alpha$ is related to the incidental photon energy by means of the following equation [16]

$$
\alpha=A\left(E-E_{g}\right) \gamma
$$

where $A$ is a constant that depends on the properties of the material, $E$ is the photon energy, $E_{g}$ is the bandgap and $\gamma$ is a constant that can take different values depending on the type of electronic transition, for a permitted direct transition $\gamma=1 / 2$, a prohibited direct transition $\gamma=$ $3 / 2$, a permitted indirect transition $\gamma=2$ and for a prohibited indirect transition $\gamma=3[17,18]$. Therefore:

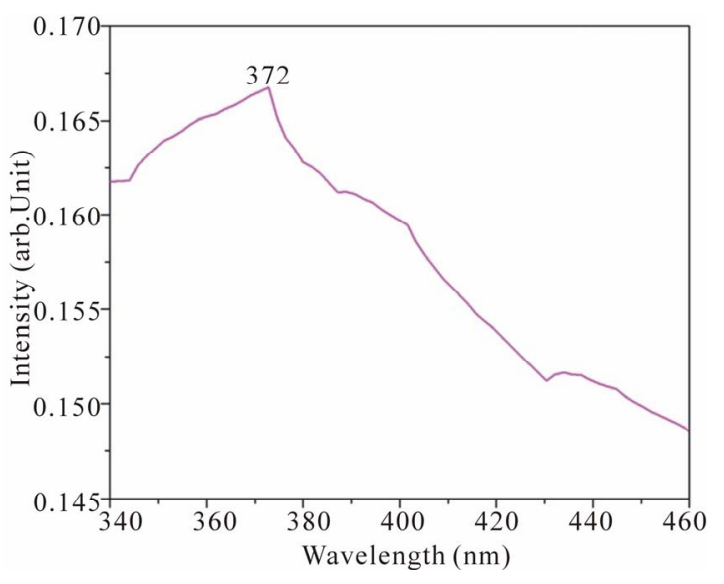

Figure 2. Shows the absorption spectrum of $\mathrm{ZnO}$.

Table 2. Comparison between standard and observed " $d$ " values of synthesized $\mathrm{ZnO}$ nanoparticles.

\begin{tabular}{ccccccc}
\hline $\begin{array}{c}\text { Observed } 2 \theta \\
\text { values }\end{array}$ & Standard $d$ & $\begin{array}{c}\text { HMTA } \\
\text { observed } d\end{array}$ & $\begin{array}{c}\text { \% of lattice } \\
\text { contraction }\end{array}$ & $(\mathrm{h}$ & $\mathrm{k}$ & $1)$ \\
\hline 31.74 & 2.8143 & 2.81645 & 0.215 & 1 & 0 & 0 \\
34.371 & 2.6033 & 2.60686 & 0.356 & 0 & 0 & 2 \\
36.20 & 2.4759 & 2.478 & 0.21 & 1 & 0 & 1 \\
47.45 & 1.9111 & 1.91314 & 0.204 & 1 & 0 & 2 \\
56.55 & 1.6247 & 1.62808 & 0.338 & 1 & 1 & 0 \\
62.80 & 1.47717 & 1.479 & 0.183 & 1 & 0 & 3 \\
67.96 & 1.3781 & 1.37967 & 0.157 & 1 & 1 & 2 \\
69.03 & 1.3582 & 1.35951 & 0.131 & 2 & 0 & 1 \\
\hline
\end{tabular}

Table 3. Morphology index, Lorentz factor and Lorentz polorization factor of $\mathrm{ZnO}$ nanoparticles for different fuels.

\begin{tabular}{ccccc}
\hline $2 \theta$ & Size & $\begin{array}{c}\text { Morphology } \\
\text { index }\end{array}$ & $\begin{array}{c}\text { Lorentz } \\
\text { factor }\end{array}$ & $\begin{array}{c}\text { Lorentz } \\
\text { polarization } \\
\text { factor }\end{array}$ \\
\hline 31.7484 & 14.497 & 0.5690 & 3.473 & 23.944 \\
34.37901 & 17.2953 & 0.6100 & 2.996 & 20.148 \\
36.20717 & 15.5469 & 0.5832 & 2.723 & 17.989 \\
47.4591 & 11.5350 & 0.4999 & 1.686 & 9.828 \\
56.55336 & 14.79347 & 0.5523 & 1.264 & 6.596 \\
62.80407 & 12.85408 & 0.5095 & 1.078 & 5.217 \\
67.96175 & 13.18045 & 0.5086 & 0.965 & 4.403 \\
69.03608 & 2.748166 & 0.1765 & 0.944 & 4.263 \\
\hline
\end{tabular}




$$
\begin{gathered}
F\left(R^{\prime} \infty\right)=\frac{\alpha}{S}=\frac{A\left(E-E_{g}\right) \gamma}{S} \\
E(\mathrm{eV})=\frac{h c}{\lambda(\mathrm{nm})}=\frac{1236}{\lambda(\mathrm{nm})}
\end{gathered}
$$

$h$ is the plank's constant and $c$ is the velocity of light.

For direct transition equation is

$$
F\left(R^{\prime} \infty\right)=\left(\frac{A}{S}\right)^{2}\left(E-E_{g}\right)
$$

For an indirect transition the equation is

$$
F\left(R^{\prime} \infty\right)^{1 / 2}=\left(\frac{A}{S}\right)^{1 / 2}\left(E-E_{g}\right)
$$

The direct band gap energy $\left(E_{g}\right)$ for the $\mathrm{ZnO}$ nanoparticles is determined by fitting the reflection data to the direct transition equation $F\left(R^{\prime} \alpha\right)^{2}$ vs $E(\mathrm{eV})$. The exact value of the band gap is determined by extrapolating the linear part of the graphics to the axis of the abscissa. The direct band gap found to be $3.5 \mathrm{eV}$ which is shown in Figure 3.

The average particle size present in the nanoparticles can be determined by using the mathematical model of effective mass approximation Equation (13) [19,20] where the particle size ( $r$, radius) and peak absorbance wavelength $(p)$ for monodispersed $\mathrm{ZnO}$ nanoparticles.

$$
r(\mathrm{~nm})=\frac{-0.3049+\sqrt{-26.23012+\frac{10240.72}{\lambda_{p}(\mathrm{~nm})}}}{-6.3829+\frac{2483.2}{\lambda_{p}(\mathrm{~nm})}}
$$

During the derivation of Equation (13), me $=0.26 \mathrm{mo}$, $m h=0.59 \mathrm{mo}$, mo is the free electron mass, $\varepsilon=8.5$, and $E_{g}$ bulk $=3.3 \mathrm{eV}$. The prepared $\mathrm{ZnO}$ nanoparticles show peak absorbance at $372 \mathrm{~nm}$ which corresponds to average particle size of $5 \mathrm{~nm}$.

\subsection{TG/DTA Analysis}

Typical TGA and DTA curves of the prepared sample powder are subjected to $8000 \mathrm{C}$ are shown in the Figure 4. TGA shows the weight loss of $2.8385 \%$. This clearly indicates that the obtained powder has extreme purity. Analysis showed that there is weight loss at $100^{\circ} \mathrm{C}$ due to the evaporation of adhesion water and above $500^{\circ} \mathrm{C}$ there is loss of weight due to loss of carbonaceous materials. In the DTA analysis there is an exothermic peak at $320^{\circ} \mathrm{C}$ might indicate the existence of organic material in small amounts.

\subsection{Particle Analyzer}

In the Figure 5 the average particle size is shown. The average particle size is calculated with the instrument HORBIA SZ100 and the scattering angle is $90^{\circ}$. The average particle size is $29 \mathrm{~nm}$. It corresponds with the crystallite size calculated from the XRD pattern.

\subsection{SEM Analysis}

The scanning electron microscopy studies were undertaken for the sample and the image is shown in the Figure 6. It is evident from the SEM micrograph that the Nano $\mathrm{ZnO}$ particles are arranged over one another in a flower shape with morphology with narrow size distribution.

\subsection{TEM Analysis}

From the dark field TEM Figure 7 it is revealed that the samples are with the average size of $20-30 \mathrm{~nm}$ which is in good agreement with that estimated by Scherer for mula based on the XRD pattern. SAED pattern is shown in Figure 8.

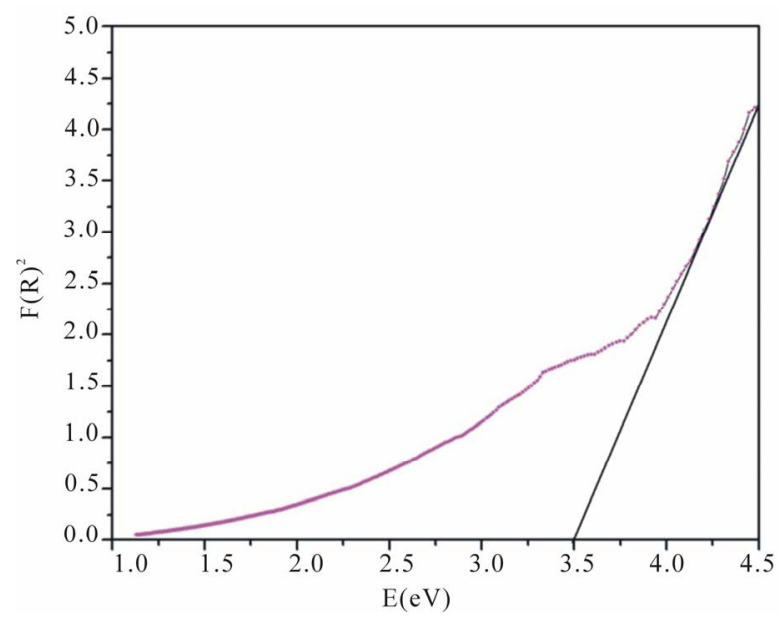

Figure 3. Band gap energy of ZnO nanoparticles.

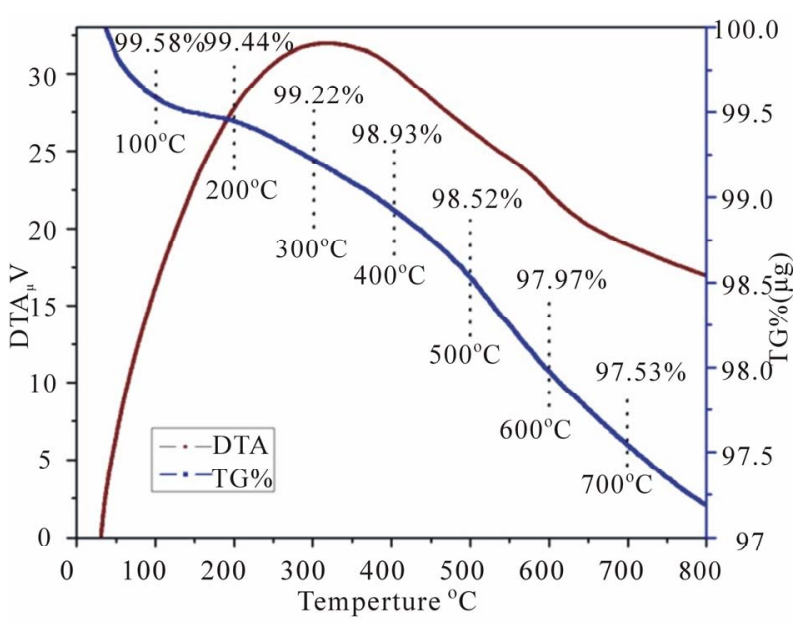

Figure 4. TGA curve of as-prepared $\mathrm{ZnO}$ nanopowder. 


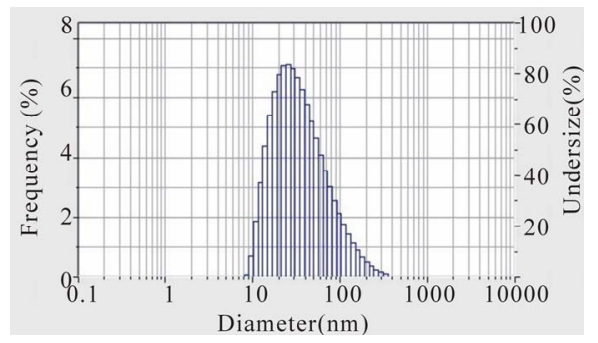

Figure 5. Particle analyzer histogram of as-prepared $\mathrm{ZnO}$ nanopowder.

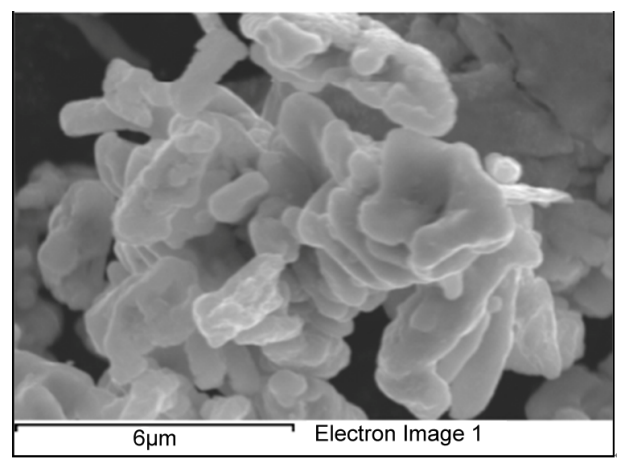

Figure 6. SEM image of as-prepared ZnO nanopowder.

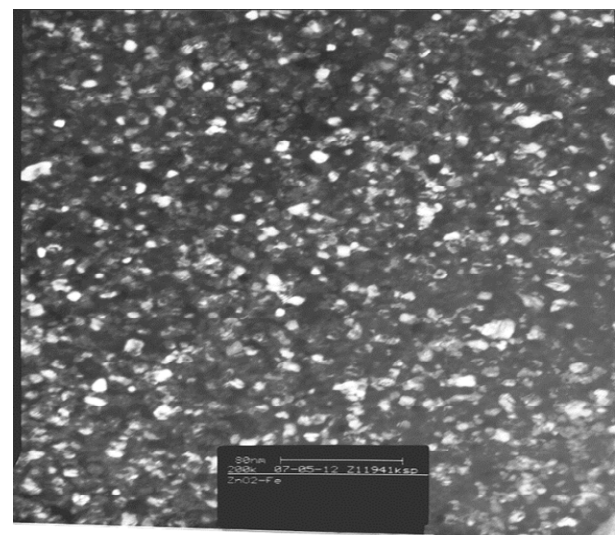

Figure 7. The dark field TEM image of nanocrystalline $\mathrm{ZnO}$.

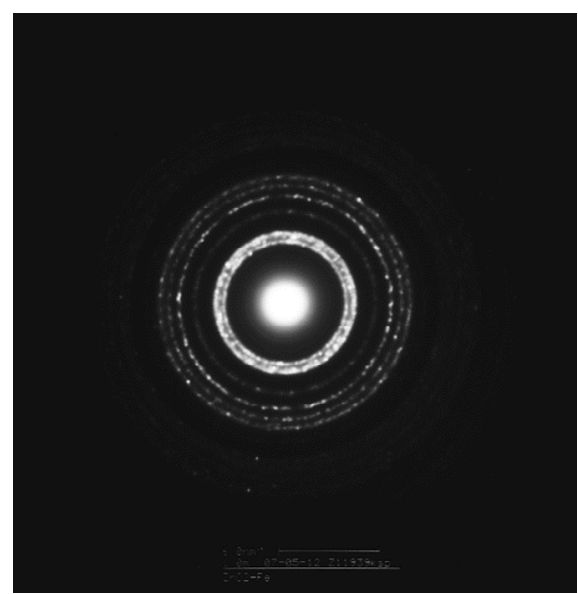

Figure 8. The SAED pattern of nanocrystalline $\mathrm{ZnO}$.

\section{Conclusion}

In this paper we have reported the synthesis of $\mathrm{ZnO}$ nano powder by fast and efficient combustion method. Using XRD data crystallite size is calculated as $21 \mathrm{~nm}$ which are in good agreement with TEM results. Further analysis showed that synthesized $\mathrm{ZnO}$ nano powder has the pure wurtzite structure with hexagonal phase. From TG/DTA weight loss was calculated to be $2.8385 \%$ which revealed that sample has high purity. Particle Analyzer supported the XRD calculations of crystallite size. SEM picture showed that particles were arranged on one another.

\section{REFERENCES}

[1] A. V. Dijkstra, E. A. Meulenkamp, D. Vanmaekelbergh and A. Meijerink, "Identification of the Transition Responsible for the Visible Emission in ZnO Using Quantum Size Effects," Journal of Luminesence, Vol. 90, No. 3, 2000, pp. 123-128. doi:10.1016/S0022-2313(99)00599-2

[2] K. R. Lee, S. Park and K. W. Lee, "Rapid Ag Recovery Using Photocatalytic ZnO Nanopowders Prepared by Solution-Combustion Method," Journal of Materials Science Letters, Vol. 22, No. 1, 2003, pp. 65-67. doi:10.1023/A:1021738526590

[3] N. Riahi-Noori, R. Sarraf-Mamoory, P. Alizadeh and A. Mehdikhani, "Synthesis of ZnO Nano Powder by a Gel Combustion Method," The Journal of Ceramic Processing Research, Vol. 9, No. 3, 2008, pp. 246-249.

[4] B. D. Cullity, "The Elements of X-Ray Diffraction," Addison-Wesley, Reading, 1978, p. 102.

[5] S. B. Bhaduri and S. Bhaduri, "Non Equilibrium Processing of Materials," Plenum, New York, 1999, p. 289. doi:10.1016/S1470-1804(99)80057-1

[6] H. S. Peiser, H. P. Rooksby and A. J. C. Wilson, "X-Ray Diffraction by Polycrystalline Materials," The Institute of Physics, London, 1955.

[7] G. L. Clark, "Applied X-Rays," 4th Edition, McGrawHill Book Company, Inc., New York, 1955.

[8] A. H. Compton and S. K. Allison, "X-Rays in Theory and Experiment,” D. Van Nostrand Company, Inc., New York, 1935.

[9] R. Willardson and A. Beer, "Optical Properties of III-V Compounds," Academic Press, New York, 1967, pp. 318400.

[10] M. Dressel and G. Gruner, "Electrodynamics of Solids Optical Properties of Electron in Matter," Cambridge University Press, Cambridge, 2002, pp. 159-165. doi:10.1017/CBO9780511606168

[11] G. Kottim, "Reflectance Spectroscopy," Springer Verlag, New York, 1969.

[12] S. Tandon and J. Gupta, "Measurement of Forbidden Energy Gap of Semiconductors by Diffuse Reflectance Technique," Physica Status Solidi, Vol. 38, No. 1, 1970, pp. 363-367. doi:10.1002/pssb.19700380136

[13] W. Wendlandt and H. Hecht, "Reflectance Spectroscopy," 
Wiley Interscience, New York, 1966.

[14] K. Sreen, C. Poulose and B. Unni, "Colored Cool Colorants Based on Rare Earth Metal Ions," Solar Energy Mater Solar Cells, Vol. 92, No. 11, 2008, pp. 1462-1467. doi:10.1016/j.solmat.2008.06.008

[15] M. Bagheri-Mohagheghi, N. Shahtahmasebi and M. Alinejad, "The Effect of the Post-Annealing Temperature on the Nano-Structure and Energy Band Gap of $\mathrm{SnO}_{2}$ Semiconducting Oxide Nano-Particles Synthesized by Polymerizing-Complexing Sol-Gel Method," Physica B: Condensed Matter, Vol. 403, No. 1, 2008, pp. 2431-2437. doi:10.1016/j.physb.2008.01.004

[16] C. Ting and S. Chen, "Structural Evolution and Optical Properties of $\mathrm{TiO}_{2}$ Thin Films Prepared by Thermal Oxidation of Sputtered Ti Films," Journal of Applied Physics, Vol. 88, No. 8, 2000, pp. 4628-4633. doi:10.1063/1.1309039

[17] S. López, S. Castillo, J. Chávez and K. Díaz, "Síntesis y
Caracterización Óptica, Eléctrica y Estructural de Películas Delgadas de CS2 Depositadas por el Método PECVD," Materia, Vol. 8, No. 4, 2003, pp. 341-349.

[18] F. Oliva, L. Avalle, E. Santos and O. Camara, "Photoelectrochemical Characterization of Nanocrystalline $\mathrm{TiO}_{2}$ Films on Titanium Substrates," Journal of Photochemistry and Photobiology A: Chemistry, Vol. 146, No. 3, 2002, pp. 175-188. doi:10.1016/S1010-6030(01)00614-1

[19] N. S. Pesika, K. J. Stebe and P. C. Searson, "Determination of the Particle Size Distribution of Quantum Nanocrystals from Absorbance Spectra," Advanced Materials, Vol. 15, No. 15, 2003, pp. 1289-1291. doi:10.1002/adma.200304904

[20] L. Brus, "Electronic Wave Functions in Semiconductor Clusters: Experiment and Theory," The Journal of Physical Chemistry, Vol. 90, No. 12, 1986, pp. 2555-2560. doi: $10.1021 / \mathrm{j} 100403 \mathrm{a} 003$ 